\title{
Espaço urbano brasileiro: entre a ditadura e a democracia - o caso de Florianópolis, SC (1964-1990)
}

\author{
Brazilian urban space: \\ between dictatorship and democracy - the case of \\ Florianopolis, SC (1964-1990)
} Reinaldo Lindolfo Lohn

Introdução: um tempo presente brasileiro

Uma História do tempo presente brasileiro deve considerar os processos que, nas últimas décadas, transformaram as cidades do país, ao mudar não apenas suas feições, mas especialmente o que podemos chamar de suas culturas ur-

Este artigo resulta do projeto de pesquisa "Cultura urbana, ditadura e democratização: relações políticas e ação estatal no litoral de Santa Catarina (1960-2000) - Grande Florianópolis e Balneário Camboriú”, desenvolvido com apoio da Universidade do Estado de Santa Catarina (UDESC).

Reinaldo Lindolfo Lohn é professor do Departamento e do Mestrado em História da UDESC, Florianópolis, Brasil (reilohn@gmail.com).

Artigo recebido em 29 de dezembro de 2010 e aprovado para publicação em 29 de março de 2011. 
banas. O foco central deste artigo consiste em abordar, numa perspectiva histórica, o espaço urbano como um dos principais âmbitos das intervenções sociais levadas a cabo pelo Estado autoritário instaurado no Brasil em 1964, com desdobramentos que marcaram os anos da abertura e da redemocratização. Para tanto, destaca-se aqui, como estudo de caso, a cidade de Florianópolis, capital de Santa Catarina, cuja população vivenciou mudanças profundas no período em apreço, com impactos socioculturais marcantes, decorrentes das iniciativas políticas que marcaram a ação estatal durante a ditadura civil-militar e a recente democratização. Seus habitantes experimentaram conflitos relacionados à conjunção de intervenções estatais e de investimentos privados durante os anos do regime autoritário e da recente democratização.

O estudo compreende o período iniciado com o golpe civil-militar de 1964 até o final da década de 1980, limites temporais correspondentes a processos históricos fundamentais para a compreensão do tempo presente brasileiro. Entre esses extremos, o país passou pela experiência de um regime ditatorial que se pautou por mecanismos autoritários de gestão do Estado, caracterizados pela imposição de uma tecnocracia que se pretendeu modernizadora e legitimada por uma suposta eficácia administrativa, bem como pela mobilização social em favor de eleições e da participação popular. O ano de 1990 encerra o contexto de consolidação de uma importante etapa da democratização do sistema político brasileiro, pela realização de eleições gerais, inclusive a escolha livre e direta, pela população, de um presidente da República, após 29 anos. Durante esse longo período, em Florianópolis e em outras cidades brasileiras, movimentos políticos, sociais e institucionais promoveram deslocamentos e rearranjos na configuração do espaço urbano, com significativos desdobramentos culturais.

Para a escrita deste artigo, além da análise de documentos oficiais e textos acadêmicos, foi empreendida a análise histórica de matérias (noticiário e propaganda) publicadas em jornais da cidade de Florianópolis. Acessar a imprensa do período permitiu a compreensão de certos "horizontes de expectativas" que marcaram a sociedade brasileira. Foram recolhidos indícios de "experiências" e "expectativas" de grupos sociais de Florianópolis (Koselleck, 2006: 305-327), relativos aos usos sociais de espaços e lugares numa cidade em mudança. As informações coletadas nos jornais possibilitaram estabelecer pontes entre as questões locais e as nacionais, de modo a recusar qualquer descrição efêmera sobre os processos aqui analisados e buscar a densidade histórica necessária para perseguir a inteligibilidade do presente (Rioux, 1999: 44-45). Foi possível perceber que ocorreu um deslocamento para o ambiente urbano de práticas e representações sociais relativas tanto à sustentação do regime ditatorial quanto à construção democrática naquelas décadas decisivas. 


\section{Cidade da ditadura}

O município de Florianópolis ocupa a ilha de Santa Catarina e a península continental adjacente. Nos anos recentes, ficou conhecido como polo turístico, em função de seus atrativos naturais, principalmente suas dezenas de praias e balneários. Ao longo do século XX não chegou a comportar um dinamismo econômico capaz de posicioná-lo entre os mais importantes do país. Contudo, seu desenvolvimento no período entre 1964 e 1990 demonstra que o repertório de práticas de gestão do espaço urbano implementado ao longo da ditadura militar e seus desdobramentos posteriores não se restringiram aos grandes centros metropolitanos.

A alavancagem da construção civil foi um dos pilares da política econômica levada a cabo pelos governos militares (Prado e Earp, 2003: 225). A ampliação do crédito, após as reformas financeiras da década de 1960, encontrou na construção residencial um canal privilegiado, consignado no I Plano Nacional de Desenvolvimento, que apontou para sua "função específica de grande absorvedora de mão de obra", demonstrada pela passagem de "785.000 em 1960, para 1.700 .000 em 1970" no número de empregos no setor. ${ }^{1}$ Essa dinâmica transformou não apenas grandes cidades, mas contribuiu para constituir um importante segmento de cidades médias. O emprego de mão de obra com baixa qualificação, com salários achatados, constituiu um meio eficaz de política habitacional, com resultados visíveis, seja na verticalização dos edifícios de apartamentos, seja nos bairros periféricos, onde grande parte da população trabalhadora encontrou como única alternativa a "autoconstrução". Juntamente com o aparato repressivo e de propaganda, as intervenções no espaço urbano foram fonte de legitimação social da ditadura.

Em 1966, uma pesquisa procurou definir o potencial do mercado imobiliário em Florianópolis, para investigar tendências pela compra de apartamentos por parte das camadas médias da cidade. A população girava em torno de $130 \mathrm{mil}$ habitantes e os anúncios publicitários, abundantes nos jornais, indicavam a preferência por morar no centro. $\mathrm{O}$ adensamento do uso e ocupação do solo no centro da cidade resultou na construção, em escala crescente, de edifícios de apartamentos, o que modificou em profundidade sua fisionomia e sua estrutura urbana. $\mathrm{O}$ desejo por adquirir apartamentos apontava para uma significativa mudança de hábitos sociais que abriu caminho para a introdução de políticas de crédito imobiliário. Funcionários públicos em cargos de chefia e profissionais liberais afirmaram-se como o grande mercado consumidor de apartamentos de três dormitórios (Pereira, s/d: 88).

O planejamento governamental e as novas oportunidades de investimento criaram um cenário novo em Florianópolis: "em cada praça, em cada avenida, 
em cada rua, em cada beco, a luz clareia os passos dos transeuntes e alimenta a beleza da nossa Ilha", que aparecia a todos "feérica" e devidamente inscrita na civilização moderna. ${ }^{2}$ Por outro lado, em fins daquela mesma década de 1960, o crescimento urbano convivia com velhos usos: "o surto de desenvolvimento que se vem verificando em nossa capital não impede que por vezes velhos carroções trafeguem pelas principais ruas da cidade. E eles respeitam sempre os sinais". ${ }^{3}$

Os governos da ditadura intensificaram o processo de montagem de uma máquina estatal complexa, com mecanismos de gestão que exigiam a constituição de segmentos burocráticos, compostos por técnicos e especialistas. Tais quadros foram selecionados entre segmentos da população que compuseram as novas camadas médias, as quais formaram um poderoso mercado de consumo urbano. O "milagre" da "revolução de 1964" foi sentido principalmente por famílias deste segmento social, desejosas por novos padrões de moradia prometidos pelos empreendedores imobiliários. O lote urbano tornou-se um dos principais fatores de apropriação de riquezas e valorização de investimentos. Em 1972 um anúncio chamava a atenção para mais um edifício construído no centro da cidade, apresentando-o como "uma homenagem ao bom gosto, à beleza e às coisas boas da vida". ${ }^{4}$ Foi um momento de apelos aos traços culturais identificadores das classes médias, com a promessa de que os projetos individuais de futuro alcançariam a plena concretização pela compra de imóveis que contivessem signos de status social.

Em 1964 foi instituído o Plano Nacional de Habitação, cuja execução seria financiada pelo Banco Nacional de Habitação $(\mathrm{BNH})$, órgão federal que compunha o Sistema Financeiro de Habitação (SFH). A captação de recursos através do recém-criado Fundo de Garantia por Tempo de Serviço (FGTS) e de letras imobiliárias - proporcionou linhas de crédito de curto prazo a construtores e de longo prazo para compradores de moradias. O sistema facilitou ainda a implantação de projetos de infraestrutura urbana. O SFH foi inicialmente composto pelo Serviço Federal de Habitação e Urbanismo (SERFHAU), pela Caixa Econômica Federal, pelo Instituto de Previdência e Assistência dos Servidores do Estado (IPASE), por caixas militares e agências de desenvolvimento regional, além de ter atuado no setor privado, através de fundações, cooperativas habitacionais, companhias de crédito imobiliário e associações de poupança e empréstimo.

As condições oferecidas pela cidade destacaram as novas classes médias no conjunto da população, especialmente após o crescimento de vagas universitárias e a instalação de sedes de empresas estatais, como a Eletrosul, subsidiária da Eletrobrás. Em poucos anos, muitos profissionais de nível superior instalaram-se na cidade, ao mesmo tempo que o acesso a cursos universitários se expandia. Sobre este último aspecto, entre 1965 e 1970, , “o total de universitários au- 
mentou 2,7 vezes [em todo o país], passando de 155 mil para 425 mil" (Almeida \& Weiss, 1998: 363). Em Florianópolis, a Universidade Federal de Santa Catarina, implantada em 1960 com 847 alunos, chegou a 1970 com 2.057 empregados, entre técnicos e professores (Pereira, s/d: 103) e com cerca de 6.000 alunos.

Uma peça publicitária da agência Propague mostrava certo personagem que em 1960, dizia: “- Investir em Florianópolis? Iihh! Nem me fale nisso!”. Já em 1962, a resposta era: “-Bem... talvez um dia eu possa investir em Florianópolis!”. Em 1964: “- Imóveis na Capital? Sim, creio que já seja possível!”. E em 1967, vários personagens apareciam sorrindo, acompanhados da mensagem: "mais de 70 pessoas de outras cidades já adquiriram imóveis em Florianópolis, somente através da Imobiliária A. Gonzaga”, para aproveitar “o rápido desenvolvimento da Capital" e todas as suas facilidades, como as praias e a universidade. ${ }^{5}$ A silhueta incorporou a imagem de altos edifícios de apartamentos, enquanto as ruas foram tomadas por automóveis.

Em estudo clássico sobre as percepções de habitantes de classe média do bairro de Copacabana, no Rio de Janeiro, Gilberto Velho (1973: 29-63) demonstrou a associação entre status social e diferenciação de classe à moradia em edifícios de apartamentos. Em Florianópolis, isso é perceptível através da publicidade de novos loteamentos, que ressaltou tais valores e acentuou a importância das mudanças em curso numa cidade que vivera sob a ameaça de perder a condição de capital estadual por suas acanhadas dimensões. Um anúncio publicitário da época afirmou que, antes do surto modernizador, "havia quem preconizasse a mudança da sede do Governo para determinada área geo-econômica do planalto". Mas, "os homens do Governo decidiram permanecer na Ilha e puseram-se a construir grandes edifícios públicos". Depois, com a ação da iniciativa privada, "começaram a subir aos ares florianopolitanos os primeiros edifícios residenciais, com seus cinco, oito e mais pavimentos". 6

\section{Expansão autoritária: espaço urbano e deslocamentos sociais}

Em 1970, um intelectual orgânico do então sistema de poder estadual, representante da tecnocracia que sustentou a ditadura, saudou o "intenso processo de mudanças" que se processava em Santa Catarina e que mobilizava a sociedade para "fazer a revolução e construir a sociedade nova com as energias emergentes do desejo de modernização". ${ }^{7}$ Referências desse tipo compuseram a formação discursiva que amparou a propaganda política dos governos militares, ao apontar para o que Carlos Fico (1997: 137) denomina "reinvenção do otimismo". A linguagem oficial associou a unidade do país a uma postura da população brasileira supostamente caracterizada pela esperança e pela crença no futuro. 
A vitória na Copa do Mundo de 1970 e, principalmente, o chamado "milagre econômico", quando foram verificados altos índices de crescimento da atividade produtiva, confirmariam o "destino de grandeza do país" e as certezas em relação ao porvir de cada brasileiro. $\mathrm{Na}$ mesma época, a campanha publicitária de um edifício de luxo em Florianópolis procurou mostrar que a nova vida urbana prometia um futuro tranquilo para as classes médias: "Solar da Baía Norte. Sem dívidas eternas, sem correção salarial e sem hipotecas.” Eis a grande vantagem: "dormir tranquilamente sem pesadelos de dívidas de 15 anos". 8

Em 1977, um possível comprador de um imóvel em uma área de grande expansão na cidade, afirmava: "precisamos viver num bairro sem a agitação e o barulho do centro. Mas com calçamento a lajotas, largas avenidas arborizadas e serviços de infraestrutura já concluídos”. Para um funcionário público de nível superior, a aquisição de um lote no local era plenamente possível: "os lotes têm metragem superior a 500 metros quadrados e são financiados em até 36 vezes com juros mínimos". 9

Paralelamente à criação de subúrbios com infraestrutura razoável e ligação com o centro, ocorreu a conurbação com os municípios vizinhos. A mobilidade da maioria da população foi garantida precariamente pelo incremento de linhas de ônibus. As cidades próximas a Florianópolis - principalmente São José, Palhoça e Biguaçu - transformaram-se em cidades-dormitório, abrigando em seus bairros periféricos uma crescente população, constituída por trabalhadores da construção civil, que encontraram ocupação nas várias obras em andamento na capital. A Companhia de Habitação do Estado (COHAB) anunciou em 1970 estar "neutralizando os efeitos de um problema social e de elevado alcance para beneficio da economia popular", com a melhoria do "orçamento dos trabalhadores", desonerados das "despesas do aluguel", numa ação "associada aos objetivos do Banco Nacional de Habitação, que teve impulso extraordinário sob as diretrizes do regime que a revolução de 1964 implantou no país". ${ }^{10}$

Os jornais dedicaram mais atenção ao novo perfil sociocultural da cidade, em especial dos milhares de trabalhadores não especializados, que afluíam à cidade em busca de oportunidades de emprego. Alguns observadores afirmaram que a transformação urbana não fora acompanhada de consequências sociais indesejáveis, pois “enquanto as massas e emigrados das grandes cidades” engrossavam "as fileiras de subempregados", na capital de Santa Catarina os migrantes eram "absorvidos nas muitas frentes de trabalho", criadas pelo "acelerado crescimento de Florianópolis nestes últimos 6 ou 10 anos".

Chegaram migrantes provenientes da zona rural de municípios próximos, como Santo Amaro da Imperatriz, Angelina e Rancho Queimado, assim como da região do Planalto Lageano, no interior do estado, em função das oscilações da indústria madeireira e dos setores agropecuários tradicionais, devido 
à modernização agrícola. As "massas recém-chegadas" encontravam emprego na "atividade econômica em franca expansão" da construção civil: "ao instante do invento de alguns milhares de emigrados", a nova atividade econômica estava "necessitada de alguns milhares de braços". ${ }^{11}$ Por outro lado, representantes da indústria da construção civil manifestaram preocupações quanto aos "milhares de trabalhadores não especializados que - afastados da lavoura pela crescente mecanização - vieram se agregar nos centros urbanos" e encontraram "a construção imobiliária" como "única atividade em que se podiam engajar". Em Florianópolis o problema seria "mais grave do que em qualquer outra cidade brasileira", pois "a indústria de Florianópolis é a indústria da construção civil". ${ }^{12}$

Até o início da década de 1970, a gestão urbana dos governos militares esteve basicamente centrada numa política habitacional dirigida às camadas médias. Após 1973, a política urbana incorporou instrumentos para a superação de desequilíbrios regionais, através de ações que preconizaram a gestão do território nacional a partir de polos urbanos (Schmidt; Farret, 1986: 33). Nesse período, os órgãos governamentais do setor foram congregados na Comissão Nacional de Regiões Metropolitanas e Política Urbana (CNPU), cuja atuação fora definida principalmente pelo II Plano Nacional de Desenvolvimento (II PND, entre 1975-1979). A estrutura estatal deveria estar tecnicamente preparada para formular políticas que estabelecessem uma melhor relação entre distribuição espacial da população e desenvolvimento econômico. As cidades constituiriam as peças a ser manipuladas como parte de um "sistema urbano" que favorecesse o controle do espaço territorial e a integração nacional.

O Plano Decenal para o período 1967-1976 estipulou mecanismos para a formulação de políticas voltadas para cidades de porte médio, adotando

uma nova concepção de política regional, denominada "regional-nacional", qual seja a de, em paralelo ao crescimento econômico, promover a integração das várias regiões do país, ideia central da estratégia de integração nacional (Steinberger \& Bruna, 2001: 39).

Essas normas estabelecidas pelo governo federal orientaram a elaboração, em Florianópolis, do Plano de Desenvolvimento Integrado da Área Metropolitana, entregue em 1971, e que serviria de base para o novo Plano Diretor, aprovado em 1976. Explicitamente, o objetivo era "a transformação de Florianópolis em um grande centro urbano, capaz de equilibrar a atração de São Paulo, de Curitiba e de Porto Alegre". Isso criaria um polo de influência no conjunto do "espaço catarinense" para catalisar "a integração e o de- 
senvolvimento harmônico do Estado" e assegurar o "objetivo nacional permanente da integração". ${ }^{13}$

O desenvolvimento urbano recebeu um capítulo específico no II PND. A meta era a resolução da dualidade entre grandes metrópoles e "a excessiva pulverização de pequenas cidades, sem um número adequado de cidades médias" que possibilitassem "equilíbrio ao conjunto". Como as cidades apareciam como responsáveis por $85 \%$ do Produto Interno Bruto, seria indispensável uma administração eficaz do espaço urbano. Isso redundaria numa "melhor estruturação do sistema urbano" que, no caso da região Sul, significava disciplinar e dinamizar o "processo de desenvolvimento do sistema urbano (...), mediante expansão ordenada das metrópoles regionais e o fortalecimento dos núcleos urbanos de médio porte". Florianópolis enquadrava-se nesta última diretriz, como centro médio a ser desenvolvido, principalmente por fazer parte do conjunto de cidades da região destinado "ao turismo e ao lazer". ${ }^{14}$

Entre as estratégias para definir e atuar sobre o "sistema urbano", em 1976 foi anunciado o Programa para Cidades de Porte Médio, cujo objetivo era "reforçar pontos do espaço nacional potencialmente capazes de 'direcionar o processo de urbanização de maneira mais racional e estruturante" e, assim, oferecer "opções aos fluxos migratórios e de capital"'. Uma noção de "desequilíbrio controlado" presidiu essa administração do espaço, pois o deslocamento populacional em busca de áreas de modernização seria inexorável. Caberia ao Estado gerir tais fluxos, principalmente no interior do país, para "tirar melhor proveito econômico da utilização do espaço brasileiro e da sua disponibilidade em recursos humanos". Foi previsto orientar o "crescimento urbano nas áreas de ocupação urbano-industrial dispersa do Estado de Santa Catarina". Entre as áreas previstas foram eleitas aquelas com "cidades de porte médio com potencial econômico ligado ao turismo e ao lazer". 15

A política urbana inseriu-se nos debates sobre a concentração de renda, nos quais "o espaço urbano aparecia como um palco de problemas e as ações da política urbana deveriam corrigir os efeitos nocivos do modelo de crescimento econômico". Segundo Marília Steinberger e Gilda Collet Bruna, ao postular a desconcentração geográfica, as formulações do período trouxeram propostas contraditórias em relação à economia de mercado. A conciliação dessa tensão dar-se-ia justamente nas cidades de porte médio, as quais aproveitariam "as vantagens das aglomerações existentes, ao mesmo tempo em que serviriam de base a uma estruturação de apoio à formação de um sistema urbano nacional mais equilibrado" (Steinberger \& Bruna, 2001: 46-47).

Em Florianópolis, a transformação do espaço urbano acertou seus passos com as orientações dos governos do regime. Obras de grande impacto urba- 
no, como o aterro da Baía Sul e a construção da nova ponte que ligou a ilha de Santa Catarina ao continente, evidenciaram que as representações sobre o futuro da cidade haviam saído dos programas governamentais e das páginas dos jornais para moldar uma nova cultura urbana. Um aspecto revelador desse processo foram as referências ao desaparecimento de formas tradicionais de comércio. Em 1972, o jornal O Estado antevia a "queda do balcão", com a "a falência dos armazéns" em decorrência da massificação da cidade e a introdução dos supermercados. ${ }^{16}$ Pode-se entender que tais mudanças no cenário urbano promoveram, numa perspectiva baseada em Stuart Hall, deslocamentos e afrouxamentos nas relações entre cultura e lugar, ao deflagrar desterritorializações na forma de "disjunturas patentes de tempo e espaço" (Hall, 2003: 36), as quais tanto implicam em recombinações híbridas, como também ameaçam de homogeneização os hábitos sociais, a partir da forte influência de mercados mais dinâmicos.

As imagens encontradas nos jornais guardam as ambiguidades de um momento histórico, marcado por deslocamentos socioculturais. Em 1974, foi noticiada a existência, em pleno funcionamento, de antigos engenhos de farinha de mandioca, atividade econômica que fora importante até o início do século XX em localidades do interior da Ilha, "um trabalho familiar, pois todos os membros de uma família proprietária de um engenho são mobilizados na época da colheita e da transformação da mandioca". Era o caso do agricultor Manoel Antônio da Silveira, que tinha 55 anos, com 21 filhos e que há 40 anos cultivava mandioca. ${ }^{17}$ No entanto, dois anos depois, no mesmo jornal, Aderbal Ramos da Silva (1911-1985), empresário e líder partidário que dominava a política local, queixava-se do "crescimento rápido" de Florianópolis, que surpreendia mesmo quem se julgava "uma pessoa conhecida na cidade", pois estava "tudo muito tumultuado, os terrenos supervalorizados pelas imobiliárias, tudo ficando estrangulado." 18

Para Yi-Fu Tuan (1983: 61-62), a sensação de "espaciosidade” derivada da vida na cidade, tomada como "um símbolo comum de liberdade no mundo ocidental", conjuga-se também a sensações contraditórias: "ser aberto e livre é estar exposto e vulnerável". A vulnerabilidade diante da presença, por vezes assustadora, de grandes populações no espaço urbano alimenta também percepções que clamam por supostas qualidades "locacionais" que as cidades teriam perdido, isto é, a condição de "centro calmo de valores estabelecidos". Entre a vulnerabilidade do espaço e a segurança do lugar, os observadores das mudanças ocorridas nas cidades ocidentais da virada do século XIX para o XX compreenderam que certas dinâmicas urbanas correspondiam a configurações e comportamentos sociais. Georg Simmel (2005: 577-591) atentou para as características das relações entre os indivíduos desenvolvidas no ambiente das grandes cidades, em especial o "caráter intelectualístico e econômico-monetário", que concorrem 
para a "mais alta impessoalidade" e a reserva diante do contato com outros: "a antipatia nos protege".

As relações históricas entre formas urbanas e seus usos sociais compreendem interações entre espaços, lugares e sociabilidades. No espaço, inscrevem-se relações e, mesmo, a passagem do tempo. A espacialização das relações sociais e da percepção das mudanças ganha uma importância inusitada em momentos de alteração das formas urbanas, ao afetar usos social e historicamente construídos. Numa linguagem derivada de Gilles Deleuze e Félix Guattari (1997: 184-185), pode-se dizer que a intenção racionalizadora de gestão dos fluxos e espaços urbanos por parte dos governos militares apresentava-se como a constituição de espaços "lisos", nos quais as cidades passavam a ser "pontos subordinados ao trajeto", ou seja, aos agenciamentos e avaliações das políticas implementadas.

A população de Florianópolis participou de uma nova temporalidade urbana que afetou redes de sociabilidade e reorganizou espaços e lugares. Modos de vida aproximaram-se daqueles predominantes em qualquer grande cidade brasileira. Na visão dos formuladores das políticas de desenvolvimento, a capital deveria assumir um papel de protagonismo sócio-econômico, como polo de atração dentro de Santa Catarina para o parque industrial localizado no interior e em expansão durante os anos do "milagre econômico". Foi essa ideia da metropolização de Florianópolis que orientaria tanto as grandes obras viárias dos anos seguintes, quanto a elaboração do Plano Diretor de 1976 (Rizzo, 1993: 59-84). Os aterros e as vias de trânsito rápido abriram espaço para automóveis que, em alta velocidade, tomaram a cidade. Para Paul Virilio (1996: 123), numa sociedade em que velocidade e poder andam juntos, "o valor estratégico do não-lugar da velocidade suplantou definitivamente o do lugar".

O prefeito de então, Esperidião Amin, que herdara a influência e o prestígio das lideranças tradicionais da cidade, encontrou respaldo nas velhas práticas políticas para exercer o domínio tecnocrático da máquina pública, ao empunhar a bandeira da modernização e do planejamento urbano. Em 1977, foi criado em sua gestão o Instituto de Planejamento Urbano de Florianópolis (IPUF). $\mathrm{Na}$ ocasião, um representante da Comissão Nacional de Política Urbana afirmou: "o planejamento urbano numa cidade ou aglomerado urbano é uma forma de justiça social". ${ }^{19}$ Os esforços e recursos públicos deveriam ser empregados para a "implantação do plano urbano de Florianópolis e área conurbada ou em processo de conurbação" (Sugai, 1994: 93-100). Mas o discurso tecnocrático apresentava limites: ao contrário do previsto pelos planos, prevaleceram os interesses políticos e empresariais que direcionaram o desenvolvimento urbano para a valorização imobiliária, como no caso de investimentos na região Norte da ilha de Santa Catarina. 


\section{A cidade na redemocratização: espaço público, apropriação privada}

A população de Florianópolis vivenciou o processo que levaria à instauração do regime democrático no país sob os ritmos urbanos de uma cidade que fora transformada nos anos da ditadura militar. Um dos cernes dos mecanismos de intervenção econômica e social do regime militar foi a política habitacional, a qual, segundo Ermínia Maricato (1987: 30), modelou cidades que ignoraram as necessidades dos "setores de menores rendimentos da população", tratando "a habitação como mercadoria a ser produzida e comercializada em moldes estritamente capitalistas". As cidades da ditadura ergueram, em geral, grandes edifícios de apartamentos, construídos por uma mão de obra com baixos salários e sem acesso ao crédito habitacional, para a qual restou a periferia, loteamentos nem sempre regulares e as favelas.

No mesmo período, as Ciências Sociais brasileiras interessaram-se pelo estudo das transformações urbanas ocorridas no Brasil, com foco nos fenômenos ocorridos nas grandes metrópoles industrializadas, caracterizadas pela "espoliação urbana", entendida como um conjunto de extorsões praticado sobre a maioria da população através da precariedade dos serviços públicos e dos baixos salários (Kowarick, 2000: 13-22). Mas é possível afirmar que muitos desses fenômenos sociais podem ser encontrados em cidades como Florianópolis, guardadas as devidas proporções.

Em meados da década de 1970, os pobres urbanos frequentavam as páginas dos jornais da cidade. Uma matéria de 1975 apresentou o morro do Mocotó, uma das áreas de pobreza urbana do centro, chamando a atenção para a "surpreendente visão, chocante, gritante, de miséria social e humana". A vida de uma habitante foi assim descrita: com seus " 25 anos, tem aspecto de 35 ", casada e com dois filhos, "na véspera de três", morava numa casa que "foi ganha". O marido recebia o salário mínimo e o casal não conseguia "pagar aluguel”. A matéria ressaltou: "ela nasceu ali, se criou, e mora até hoje". A matéria trouxe como novidade abordar o morro simplesmente como "uma favela, um amontoado de casas encarapitadas numa encosta de morro, suspensas pela vontade, pela necessidade de habitar e não exigir nada, não pela falta de direitos, mas pela total inexequibilidade de pedi-los". Essa representação do local, porém, contrariava os moradores: "a palavra favela se aplica a contragosto. O termo não é bem-vindo". Afinal, "eles formam uma comunidade homogênea". 20

A representação da população pobre a partir de uma linguagem própria às grandes cidades brasileiras causou menos estranheza quando dirigida ao fenômeno do crescimento de novas áreas periféricas. Esses assentamentos receberam uma população com outro perfil demográfico, atribuído ao "movimento migratório em Santa Catarina" que tinha na capital "o ponto preferido de todos quan- 
do abandonam os campos na esperança de encontrar melhores perspectivas de vida nas cidades". O grande problema era "a falta de habitação" para as "famílias que se deslocam do interior para Florianópolis" e, assim, "o número de favelas se avoluma, ganhando os espaços vazios que margeiam a cidade e se espalhando pelos municípios vizinhos à Capital do Estado". ${ }^{21}$

Áreas recentemente ocupadas, habitadas por populações em piores condições de vida, eram as que apresentavam os conflitos sociais mais graves. Em 1979 , as constantes ameaças de remoção e desalojamento atingiram "os moradores mais pobres" de uma região que crescera aceleradamente naquela década, dada a proximidade com a Universidade Federal de Santa Catarina. Os habitantes mostravam-se "apavorados com as pressões" de órgãos públicos que pretendiam "tirá-los de lá". Eram pessoas, na grande maioria, provenientes "de municípios do interior do Estado, desalojadas de suas terras e por motivos econômicos, a procura de melhores condições de vida". ${ }^{22}$ No morro da Caixa, na área continental, um morador declarou: "não saímos daqui assim. Nem que eles metam os tratores em cima da gente". As famílias do local foram ameaçadas de remoção para loteamentos distantes, em municípios vizinhos. ${ }^{23}$

Neste cenário operaram-se deslocamentos socioculturais que ajudaram a evidenciar novas culturas urbanas, no momento em que o país começou a experimentar uma transição política. As sucessivas vitórias eleitorais do partido da oposição consentida durante a ditadura, o Movimento Democrático Brasileiro (MDB), acompanharam a crise que se sucedeu ao esgotamento do "milagre econômico". As grandes cidades, com uma população de trabalhadores incorporada ao processo de modernização, passaram a ser um foco de dissabores constantes para os apoiadores do regime ditatorial, ao passo em que as demandas sociais não eram atendidas e as condições de sobrevivência dos mais pobres pioravam gradativamente. Enquanto o regime procurava a todo custo, através do endividamento externo (Furtado, 1981: 48), manter sem sucesso o ritmo de crescimento, os jornais noticiavam, em 1979, o abandono, "por falta de recursos", de projetos de habitação do BNH em Florianópolis, ao mesmo tempo em que a inflação corroía os salários. ${ }^{24}$

Os novos espaços urbanos criados sob a égide dos investimentos públicos e privados em construção civil e desenvolvimento de infraestrutura apresentaram as contradições sociais de uma sociedade que havia se tornado mais complexa. Por essa época, em várias partes do país, e em Florianópolis não foi diferente, as novas experiências das camadas populares, decorrentes de um cotidiano compartilhado por milhões de habitantes de cidades que sofreram profundas transformações, passaram a incorporar temas como cidadania e direitos civis, políticos e sociais. 
Movimentos de base-organizados nas igrejas, nas escolas ou mesmo em entidades partidárias - congregaram esforços locais no sentido de praticar uma democratização no cotidiano (Sader, 1988: 99-114). A representação dos pobres como portadores de direitos e capazes de agir socialmente, por suas próprias forças, em busca de participação política e melhorias de vida, moveu ativistas e associações. Em Florianópolis era notório o emprego, até então, de estratégias de melhorias dos bairros pobres através da ação de cabos eleitorais "que forjavam uma interligação com as autoridades governamentais". Maristela Fantin (1997: 138-141) destaca que essas práticas passaram a sofrer a concorrência de ações de movimentos organizados, como o caso da Pastoral Universitária, que realizaram trabalhos de educação popular no início da década de 1980, sob a inspiração de Paulo Freire e da Teologia da Libertação, para a conquista de serviços públicos essenciais.

As disputas sociais que envolveram a constituição de espaços públicos e de territórios atravessados por novas relações sociais são elemento indispensável para compreender os desdobramentos da construção democrática no Brasil. Como parte dos processos políticos que forçavam a abertura do regime autoritário e a democratização, o espaço urbano converteu-se, efetivamente, em espaço público e abrigou amplas mobilizações pela democracia. Em Florianópolis, um momento marcante ocorreu em novembro de 1979, quando uma manifestação estudantil em protesto contra a visita do general-presidente João Figueiredo transformou-se num levante popular que tomou as ruas do centro da cidade. Nos dias seguintes, outras manifestações exigiram a liberdade de estudantes presos no movimento, conhecido depois como "Novembrada". 25

Foi um momento em que as praças e ruas das capitais brasileiras tornaram-se, segundo Lucília de Almeida Neves Delgado (2007: 414-415), "o espaço privilegiado para a defesa de importantes aspirações republicanas". Em todo o país, as mobilizações sociais intensificaram-se e atingiram seu ápice com a simbólica campanha em favor de eleições diretas para a presidência da República, entre 1983 e 1984. Do mesmo modo, as cidades abrigaram outras formas de manifestação, inclusive protestos populares, que reclamavam melhores condições de vida e reivindicavam ações e investimentos públicos. As cidades assumiram uma dimensão fundamental na representação das multidões que formariam um povo em busca de cidadania e democracia (Jacobi \& Nunes, 1982: 189-198). Do ponto de vista institucional, o processo de democratização em Florianópolis teve como resultado visível a vitória de Édson Andrino, candidato do Partido do Movimento Democrático Brasileiro (PMDB), nas primeiras eleições na cidade após a ditadura, realizadas em 1985, sobre Francisco de Assis Filho, candidato apoiado pelo governador Esperidião Amin, artífice político mais diretamente vinculado ao processo de modernização urbana da década anterior. 
Por outro lado, ao longo da década de 1980, estudos como o de Teresa Pires do Rio Caldeira (2000: 314-323) apontam para um movimento oposto: a "implosão da vida pública moderna", através de formas de sociabilidade pautadas na privatização das relações entre os indivíduos e dos serviços urbanos. A segregação sócio-espacial tornou-se visível nas grandes aglomerações urbanas brasileiras, praticada pelas camadas médias e altas da população em relação aos pobres. A proliferação de crimes violentos, associada a fenômenos como a organização do tráfico de drogas, acentuou tais práticas sociais. Para Marcelo Lopes de Souza (2008: 69), o "planejamento estadocêntrico" entrou em decadência ao final da ditadura e foi sucedido por fenômenos sociais que ensejaram condições para o que chama de "fobópole", quando, em meio ao restabelecimento de liberdades civis, a questão urbana foi militarizada.

A difusão de uma linguagem caracterizada pelo medo e que descreveu o cotidiano da vida urbana como "gerra civil" extravasou das grandes cidades para todo o país, "com a sensação de insegurança" e a proliferação de "condomínios exclusivos". Em Florianópolis, o apelo ao discurso da segurança e da reclusão ganhou as páginas de jornais no início da década de 1980: "dormir tranquilo é uma coisa que o florianopolitano já não pode há algum tempo. A preocupação já é uma constante". ${ }^{26}$ Ao longo da década, a "demanda crescente por ordem" alimentou o voto conservador em várias cidades brasileiras, ao exigir dureza policial e garantir o sucesso de políticos pouco comprometidos com a democratização (Zaluar, 2004: 215).

A década começara com uma profunda crise do setor da construção civil em Florianópolis, com cerca 48\% de empreendimentos paralisados: "o grande problema é o achatamento salarial a que foi e está submetida a classe média, cada vez mais descapitalizada”. No período entre 1973 e 1976, cerca de 35 edifícios residenciais haviam sido construídos anualmente para as camadas médias, mas apenas seis estavam em andamento em 1981. Os empreendimentos populares estavam completamente parados: "não há nenhum agente credenciado na cidade, do Sistema Financeiro da Habitação, que esteja financiando casas e apartamentos avulsos". ${ }^{27}$ As dificuldades governamentais refletiram-se em salários defasados para funcionários públicos, o grande mercado consumidor de imóveis da década anterior. Para esse público restou a procura por alternativas de moradia mais simples e baratas em áreas afastadas, que foram ofertadas por pequenos e médios empreendedores (Campos, 2004: 125).

$\mathrm{Na}$ esteira da crise econômica que acompanhou os primeiros anos da chamada Nova República, o processo de urbanização de Florianópolis passou a ser alvo de constantes disputas sociais e políticas. Os baixos rendimentos, o desemprego e o crescimento das áreas de ocupação por populações de baixa renda acentuaram a percepção de desigualdade social. As organizações de base, que demandavam novos di- 
reitos sociais para a população, entraram em choque com grupos políticos e empresariais que procuravam ativar oportunidades de investimento privado. Enquanto o processo de democratização política consolidava-se no país, os grupos dirigentes de Florianópolis estabeleceram uma convivência conflituosa com os movimentos populares e ambientalistas. Ao mesmo tempo, desenvolveram instrumentos de comunicação e adesão social para assegurar apoio político para a transformação da cidade, pretensamente, num polo imobiliário e turístico.

A administração pública e as redes de políticos e empresários ligados aos setores hoteleiros e da construção civil apoiaram as iniciativas que visavam construir imagens que investiam na representação de Florianópolis como lugar de segurança e tranquilidade, atrativos capazes de interessar a um público consumidor de alta renda, proveniente de grandes cidades marcadas pela violência urbana. Uma linguagem padronizada, emitida pela mídia e por lideranças políticas, apontava para a vocação turística da cidade. A retórica de desenvolvimento estatal da década anterior foi abandonada e os setores que compunham as redes de poder lançaram mão de novas estratégias, com as quais procuraram governar o urbano a partir da perspectiva de iniciativas empreendedoras, voltadas para o mercado turístico e imobiliário (Harvey; Smith, 2005: 42-47).

Em 1984, o anúncio de um grande empreendimento imobiliário no norte da ilha, que construiu um balneário para um mercado de alta renda, convidava: "venha para Jurerê Internacional. E ganhe toda a Ilha de Santa Catarina como brinde". ${ }^{28}$ A mitificação da Ilha foi complementada ao final da década, com a identificação publicitária "Ilha da Magia", que fazia referência aos trabalhos de Franklin Cascaes (1908-1983), artista plástico e folclorista local, que durante boa parte de sua vida retratou o processo de modernização da cidade como uma perda de traços culturais tradicionais.

Os investimentos imobiliários ganharam outra dimensão, diferente da década anterior, ao deslocar-se para a exploração de um imaginário construído no âmbito da publicidade turística. A noção de "lugar" é particularmente importante para compreender as implicações sociais das iniciativas que pretenderam transformar Florianópolis em polo de turismo na década de 1980. A emergência de um "espaço nômade", constituído de fluxos de capital, "tem deslocado o sentido das práticas sociais de certas configurações espaço-temporais concretas". Segundo Rogério Proença Leite (2007: 34-60), "essa deslocalização" redefine certos âmbitos "mais perenes da vida social": as articulações entre "identidade e lugar". Durante os governos da ditadura militar, "tendo como principal orientação o desenvolvimento do turismo", a atribuição de valor histórico e cultural a bens e lugares passou para a esfera das cidades, que foram investidas de legitimidade para definir políticas locais de patrimonialização e, por extensão, de constituição de ambientes urbanos apresentados como bens culturais. 
Essas ações tiveram continuidade durante os governos da Nova República, com o acréscimo de que o poder público foi incentivado a estabelecer parcerias com a iniciativa privada. Tais mecanismos ensejaram a constituição de um mercado para o "consumo de lugares" situados nas cidades. No caso de Florianópolis, isso foi expresso em ações voltadas para valorizar recantos pitorescos e naturais da ilha de Santa Catarina. Foram operadas estratégias de promoção e marketing para apresentar a cidade através do invólucro de identidades estáveis e autênticas, mesmo que inscritas nos percursos mercantis mais amplos do turismo e da especulação imobiliária em nova escala.

Nessa toada, configurou-se um espaço urbano fragmentado e dividido entre balneários muito valorizados e núcleos urbanos dispersos, ligados por rodovias congestionadas e um transporte coletivo ineficiente. Em uma década, a população da cidade cresceu cerca de $35 \%$ e aproximou-se de 260 mil pessoas, sendo que a região conurbada chegou a meio milhão de habitantes. Em meio à crise econômica, os investimentos imobiliários apareceram como a aposta segura em Florianópolis: "compre solidez, compre imóvel", ${ }^{29}$ ou ainda "não deixe a inflação engolir sua poupança: invista em imóveis, a melhor poupança”. ${ }^{30} \mathrm{~A}$ Prefeitura, novamente sob o comando de Esperidião Amin, vencedor das eleições de 1988, lançou a campanha publicitária "Florianópolis vale a pena", de modo a atrair investidores. Enquanto isso, o desejo de construir a segunda casa na praia tomou conta dos segmentos de classe média e alta locais. Em 1989, a administração pública, com o apoio de investidores privados, apresentou propostas para inscrever Florianópolis num circuito de turismo internacional, acompanhadas por despejos e remoções de favelas (Lisboa et al, 1996: 184).

Ao longo da década de 1980, enquanto a sociedade mobilizou-se e questionou o Estado centralizador e autoritário, o mercado assumiu um papel predominante na configuração das cidades como Florianópolis, que se transformaram em lugares sujeitos à lógica da mercadoria, o que veio a conflitar com as iniciativas para a democratização do espaço urbano. Na acepção de Bernard Lepetit (2001: 140-141), “a cidade não é um palimpsesto" e, sendo assim, "cidade não dissocia: ao contrário, faz convergir, num mesmo tempo, os fragmentos de espaço e os hábitos vindos de diversos momentos do passado". Nessa compreensão, "as mudanças sociais de uso determinam as modalidades de resistência e a duração da vida do construído, muito mais do que o inverso". Pode-se então pensar que a ditadura não foi simplesmente apagada do espaço das cidades brasileiras, posto que muitos usos sociais ainda esperam pela democratização das sociabilidades urbanas, para além das expectativas das camadas privilegiadas da sociedade.

Através desse estudo foi possível discutir as relações e os deslocamentos que se fizeram presentes na interface entre espaços urbanos e os processos socio- 
culturais e políticos que compreenderam o período da ditadura civil-militar e a recente democratização brasileira. Florianópolis foi tomada como parte de uma reflexão histórica sobre a ação do Estado e dos mecanismos de planejamento urbano durante os anos da ditadura militar e seus desdobramentos, quando a sociedade passou a respirar ares democráticos. Compreendeu-se, aqui, que as formas e os usos de uma cidade não são necessariamente simétricos. As interações e os cruzamentos entre formas urbanas delineadas sob perspectivas autoritárias e usos sociais pautados pela convivência ambígua com a democracia são elementos de uma problemática a ser compreendida para a escrita de uma História do tempo presente brasileiro.

Notas

1. BRASIL. Lei $\mathrm{n}^{\circ}$. 5.727, de 4 de novembro de 1971. Dispõe sobre o Primeiro Plano Nacional de Desenvolvimento (PND), para o período de 1972 a 1974. Disponível em: http://www6.senado.gov.br/legisla cao/ListaPublicacoes.action $? \mathrm{id}=120837$. Acesso em 09 ago. de 2010.

2. A Gazeta, Florianópolis, 8 de novembro de 1964, p. 1.

3. O Estado, Florianópolis, 25 de abril de 1967, p. 1.

4. O Estado, Florianópolis, 10 de julho de 1972, p. 4.

5. A Gazeta, Florianópolis, 4 de julho de 1967, p. 2.

6. O Estado, Florianópolis, 28 de junho de 1966, p. 4.

7. ABREU, Alcides et al. Ensaios sobre a economia catarinense. Florianópolis: Edeme, 1970, p. 7-25.

8. O Estado, Florianópolis, 17 de agosto de 1970, p. 3.

9. Bom Dia Domingo, Florianópolis, 18 de dezembro de 1977, p. 5.
10. O Estado, Florianópolis, 3 de março de 1970, p. 3.

11. O Estado, Florianópolis, 11 de setembro de 1977, p. 33.

12. Bom Dia Domingo, Florianópolis, $20 \mathrm{de}$ novembro de 1977, p. 8.

13. ESCRITÓRIO CATARINENSE DE DESENVOLVIMENTO INTEGRADO.

Plano de desenvolvimento da área metropolitana de Florianópolis. Florianópolis: [s.ed], 1971, p. 5-8.

14. BRASIL. Plano Nacional de Desenvolvimento, 2. São Paulo: Sugestões Literárias, 1975, p. 71-75.

15. PEDD: Planejamento e Desenvolvimento. Política Urbana: programa para cidades de porte médio. Brasilia: Secretaria de Planejamento da Presidência da República, Coordenadoria de Comunicação Social, v. 3, n. 36, maio/1976, p. 20-25.

16. O Estado, Florianópolis, 6 de agosto de 1972, p. 4.

17. O Estado, Florianópolis, 31 de março de 1974, p. 8 . 
18. O Estado, Florianópolis, 14 de maio de 1976, p. 16.

19. O Estado, Florianópolis, 25 de maio de 1977, p. 16.

20. O Estado, Florianópolis, 12 de junho de 1975, p. 8.

21. O Estado, Florianópolis, 23 de abril de 1977, p. 1.

22. O Estado, Florianópolis, 14 de outubro de 1979, p. 16.

23. O Estado, Florianópolis, 17 de outubro de 1979, p. 16.

24. O Estado, Florianópolis, 27 de outubro de 1979, p. 5.

\section{Referências bibliográficas}

ALMEIDA, Maria Hermínia T. de \& WEIS, Luiz. Carro-zero e pau-de-arara: o cotidiano da oposição de classe média ao regime militar. In: SCHWARCZ, Lilia Moritz (org.) História da vida privada no Brasil, 4: contrastes da intimidade contemporânea. São Paulo: Cia das Letras, 1998. p. 319-410.

CALDEIRA, Teresa Pires do Rio. Cidade de muros: crime, segregação e cidadania em São Paulo. São Paulo: Editora 34/EDUSP, 2000.

CAMPOS, Edson Telê. $A$ expansão imobiliária e seus impactos ambientais em Florianópolis. Florianópolis: Insular, 2004.

DELEUZE, Gilles \& GUATTARI, Félix. Mil platôs: capitalismo e esquizofrenia, vol. 5 . São Paulo: Ed. 34, 1997.

DELGADO, Lucília de Almeida Neves. Diretas Já: vozes das cidades. In: FERREIRA, Jorge \& REIS, Daniel Aarão. As esquerdas no Brasil, 3: revolução e democracia
25. $O$ Estado, Florianópolis, 5 de dezembro de 1979, p. 3.

26. A Ponte, Florianópolis, junho de 1981, p. 2.

27. O Estado, Florianópolis, 21 de dezembro de 1981, p. 12.

28. O Estado, Florianópolis, 2 de dezembro de 1984, p. 4.

29. O Estado, Florianópolis, 3 de maio de 1987, p. 5.

30. Diário Catarinense, Florianópolis, 6 de agosto de 1988, p. 9.

(1964-...). Rio de Janeiro: Civilização Brasileira, 2007, p. 409-427.

FANTIN, Maristela. Construindo cidadania e dignidade. Florianópolis: Insular, 1997.

FICO, Carlos. Reinventando o otimismo: ditadura, propaganda e imaginário social no Brasil. Rio de Janeiro: Ed. FGV, 1997.

FURTADO, Celso. O Brasil "pós-milagre". Rio de Janeiro: Paz e Terra, 1981.

HALL, Stuart. Da diáspora: identidades e mediações culturais. Belo Horizonte: Ed. UFMG, 2003.

HARVEY, David \& SMITH, Niel. Capital financiero, propiedad inmobiliaria y cultura. Barcelona: Museu d'Art Contemporani de Barcelona/Universitat Autônoma, 2005.

JACOBI, Pedro \& NUNES, Edison. Movimentos populares urbanos, poder local e conquista da democracia. In: MOISÉS, 
José Álvaro et al. Cidade, povo e poder. Rio de Janeiro: Paz e Terra, 1982. p. 165-198.

KOSELLECK, Reinhart. Futuro passado: contribuição à semântica dos tempos históricos. Rio de Janeiro: Contraponto/PUC-Rio, 2006.

KOWARICK, Lúcio. Escritos urbanos. São Paulo: Ed. 34, 2000.

LEITE, Rogério Proença. Contra-usos da cidade: lugares e espaço público na experiência urbana contemporânea. Campinas: Ed. Unicamp; Aracaju: Ed. UFS, 2007.

LEPETIT, Bernard. Por uma nova história urbana. São Paulo: Ed. USP, 2001.

LISBOA, Armando de Melo et al. Uma cidade numa ilha: relatório sobre os problemas sócio-ambientais da Ilha de Santa Catarina. Florianópolis: Insular, 1996.

MARICATO, Ermínia. Política habitacional no regime militar: do milagre brasileiro à crise econômica. Petrópolis: Vozes, 1987.

PEREIRA, Nereu do Vale. Desenvolvimento e modernização: um estudo de modernização em Florianópolis. Florianópolis: Lunardelli, s/d.

PRADO, Luiz Carlos Delorme \& EARP, Fábio Sá. O "milagre" brasileiro: crescimento acelerado, integração nacional e concentração de renda. In: FERREIRA, Jorge \& DELGADO, Lucília de A. Neves (orgs.). O Brasil republicano, 4: o tempo da ditadura. Regime militar e movimentos sociais em fins do século XX. Rio de Janeiro: Civilização Brasileira: 2003, p. 207-242.

RIOUX, Jean-Pierre. Pode-se fazer uma História do presente? In: CHAUVEAU, Agnès \& TÉTARD, Philippe. Questões para a História do presente. Bauru, SP: Edusc, 1999, p. 39-50.

RIZZO, Paulo Marcos Borges. Do urbanismo ao planejamento urbano: utopia e ideologia. Caso de Florianópolis - 1950 a 1990...
Dissertação (Mestrado em Geografia) Universidade Federal de Santa Catarina, Florianópolis, 1993.

SADER, Eder. Quando novos personagens entraram em cena: experiências e lutas dos trabalhadores da Grande São Paulo (1970-1980). Rio de Janeiro: Paz e Terra, 1988.

SCHMIDT, Benício \& FARRET, Ricardo. A questão urbana. Rio Janeiro: Jorge Zahar, 1986.

SIMMEL, Georg. As grandes cidades e a vida do espírito (1903). Mana, Rio de Janeiro, vol. 11, n. 2, 2005.

SOUZA, Marcelo Lopes de. Fobópole: o medo generalizado e a militarização da questão urbana. Rio de Janeiro: Bertrand Brasil, 2008.

STEINBERGER, Marília \& BRUNA, Gilda Collet. Cidades médias: elos do urbano-regional e do público-privado. In: ANDRADE, Thompson Almeida \& SERRA, Rodrigo Valente (orgs.). Cidades médias brasileiras. Rio de Janeiro: IPEA, 2001, p. 35-77.

SUGAI, Maria Inês. As intervenções viárias e as transformações do espaço urbano: $A$ via de contorno norte-Ilha. Dissertação (Mestrado em Arquitetura e Urbanismo, 2 v.) - Faculdade de Arquitetura e Urbanismo, Universidade de São Paulo. São Paulo, 1994.

TUAN, Yi-Fu. Espaço e lugar: a perspectiva da experiência. São Paulo: Difel, 1983.

VELHO, Gilberto. A utopia urbana: um estudo de antropologia social. Rio de Janeiro: Zahar, 1973.

VIRILIO, Paul. Velocidade e política. São Paulo: Estação Liberdade, 1996.

ZALUAR, Alba. Crime, medo e política. In: ZALUAR, Alba \& ALVITO, Marcos (orgs.). Um século de favela. Rio de Janeiro: Editora FGV, 2004, p. 209-232. 


\section{Resumo}

Este artigo aborda as intervenções no espaço urbano durante a ditadura militar e os primeiros anos da recente democratização política do Brasil, com foco no caso de Florianópolis, capital de Santa Catarina, entre 1964 e 1990. Nesse período, diversos segmentos sociais mobilizaram-se contra o Estado autoritário, mas as relações de mercado assumiram um papel proeminente na moldagem de cidades como Florianópolis, o que conflitou com as iniciativas de democratização do espaço urbano. A questão que motiva o trabalho é o estudo das interações entre as formas urbanas delineadas durante a ditadura e os usos sociais configurados pela convivência democrática.

Palavras-chave: espaço; lugar; ditadura; democracia; cultura urbana; tempo presente.

\section{Abstract}

This article discusses the interventions in urban space during the military dictatorship and the early years of the recent political democratization of Brazil, focusing on the case of Florianópolis, capital of Santa Catarina, between 1964 and 1990. During this period several social groups mobilized against the authoritarian State, but market relations took a prominent role in shaping cities like Florianopolis, which conflicted with the efforts of democratization of urban space. The question that motivates the work is the study of interactions between urban form imposed during the dictatorship and the social uses configured for democratic coexistence.

Keywords: space; place; dictatorship; democracy; urban culture; present time.

\section{Résumé}

Cet article décrit les interventions dans l'espace urbain pendant la dictature militaire et les premières années de la démocratisation politique récente du Brésil, en se concentrant sur le cas de Florianópolis, capitale de Santa Catarina, entre 1964 et 1990. Au cours de cette période, plusieurs groupes sociaux se sont mobilisés contre l'Etat autoritaire, mais les relations de marché a pris un rôle prépondérant dans le façonnement des villes comme Florianopolis, qui était en contradiction avec les efforts de démocratisation de l'espace urbain. La question qui motive le travail est l'étude des interactions entre la forme urbaine imposée au cours de la dictature et les usages sociaux configurés pour la coexistence démocratique.

Mots-clés: espace; lieu; dictature; démocratie; culture urbaine; temps présent. 